\title{
Letters
}

Website: www.bmj.com

Email: letters@bmj.com

\section{People who condemn eugenics may be in minority now}

EDITOR-In concluding his article on eugenics, Kevles should not have used the words "History at the least has taught us ..." because they imply that most people condemn eugenics now. ${ }^{1}$ Those who condemn eugenics may actually be a minority. In China, where the population exceeds 1.2 billion, geneticists overwhelmingly support eugenics. ${ }^{2}$ India, Russia, and other populous countries share China's views on genetic issues. $^{2}$

The social values that guided early Western eugenicists and still underlie Chinese eugenics "give greater importance to the well-being of social groups than that of the individual."' By contrast, current Western values, concerned as they are with individual rights rather than with the common good, ${ }^{3}$ represent the exact opposite of both Chinese values and the social ethics that evolution fostered for millions of years-social ethics that proved to be the best ethics for ensuring the survival of social groups. ${ }^{4}$

Paraphrasing Kevles's words, I suggest that evolution should teach us that current Western values focusing on the good of the individual, not on the good of society, are

\footnotetext{
Advice to authors

We prefer to receive all responses electronically, sent either directly to our website or to the editorial office as email or on a disk. Processing your letter will be delayed unless it arrives in an electronic form.

We are now posting all direct submissions to our website within 24 hours of receipt and our intention is to post all other electronic submissions there as well. All responses will be eligible for publication in the paper journal.

Responses should be under 400 words and relate to articles published in the preceding month. They should include $\leqslant 5$ references, in the Vancouver style, including one to the BMJ article to which they relate. We welcome illustrations.

Please supply each author's current appointment and full address, and a phone or fax number or email address for the corresponding author. We ask authors to declare any competing interest. Please send a stamped addressed envelope if you would like to know whether your letter has been accepted or rejected.

Letters will be edited and may be shortened.

www.bmj.com

letters@bmj.com
}

both near sighted and intrinsically unethical, because they create more pain than they prevent. Those values, to spare a few individuals bearable sorrow, cause untold suffering to many people. In China the grief of those who are not allowed to procreate on eugenic grounds is unquestionably far less tragic than the perpetuated pain of their potential, numerous descendants.

Although Chinese eugenics has patently nothing whatever to do with the murders committed by Nazis, many Westerners condemn it because Hitler supported eugenics. As Nobel prizewinner James D Watson pointed out, however, "We must not fall into the absurd trap of being against everything Hitler was for. It was in no way evil for Hitler to regard mental disease as a scourge on society.... Because of Hitler's use of the term Master Race, we should not feel the need to say that we never want to use genetics to make humans more capable than they are today."

Should Western countries espouse eugenics, they will hardly be condemned for it by future generations enjoying long and healthy lives. Conversely, if Westerners continue to disapprove of eugenics they will probably be hated by generations to come for not having avoided transmitting to them some conditions that can lead affected people to regret the day they were born.

Riccardo Baschetti medical inspector (retired) Italian State Railways, CP 1011, 35100 Padua, Italy baschetti@shineline.it

Kevles DJ. Eugenics and human rights. BMJ 1999;319: 435-8. (14 August.)

2 Dickson D. Survey: some countries side with China on genetic issues. Nature Med 1998;4:1096.

Dickson D. Congress grabs eugenics common ground Nature 1998;394:711.

Baschetti R. Evolutionary psychiatry. J R Soc Med 1997 90:358-9.

5 Watson JD. Genes and politics. J Mol Med 1997;75:624-36.

\section{Treatment of toenail onychomycosis}

Will paper's key message soon appear in promotional material for drug?

EDITOR-Evans and Sigurgeirsson show that one form of treatment for toenail onychomycosis (continuous terbinafine) is significantly better than another (intermittent itraconazole). ${ }^{1}$ But I find it disturbing that the journal has given such prominence (the first paper in the journal and the first item in
This Week in the $B M J$ ) to a comparative drug trial of two well established drugs that was financed entirely by the manufacturer of one of the drugs.

The introduction to the paper cites a prevalence of onychomycosis of 2-4\%, yet the study population consisted of patients with severe onychomycosis (on average a 10 year history with six toenails affected; this fact is tucked away in the last paragraph). No evidence is presented to show the relevance of the study to a wider population of patients with mild or moderate onychomycosis.

The optimistic key message (repeated in This Week in the $B M$ ) that "fungal nail disease is curable" is correct only in the sense that about half of the patients who took terbinafine showed a complete cure at 72 weeks. This accords with Epstein's recent review of the success of oral treatment of onychomycosis. ${ }^{2}$ Would it not have been equally true (although more pessimistic, and certainly less promotional) to say "fungal nail disease is incurable"?

The paper states: "As with the mycological cure rates the clinical cure rates for the continuous terbinafine groups continued to increase after treatment through to week 72 . This was not the case for the intermittent itraconazole groups." The graphs on p 1034, however, tell a different story. They show that the cure rates for both forms of treatment continued to increase substantially after treatment stopped.

I was particularly disturbed to see that the authors acknowledged the "constant help and guidance throughout this project" of an employee of Novartis Pharmaceuticals Corporation. Why, I asked myself, was it necessary to have the constant help and guidance of the manufacturer of one of the drugs being studied?

As a general practitioner who often receives letters from podiatrists asking me to prescribe 12-16 week courses of systemic terbinafine for relatively mild and insignificant nail discoloration, I am also concerned about the cost (£134-£178) and the cost-benefit analysis of such treatment. I predict that the paper's final key message"Continuous terbinafine should be the current treatment of choice for onychomycosis"-will soon appear in promotional material for terbinafine. But is it a claim that should be made in the scientific pages of the $B M J$, or should it be confined to the advertisements?

Fred Kavalier general practitioner

Kentish Town Health Centre, London NW5 2BX kavalier@londonmail.com

Competing interests: None declared. 
1 Evans EGV, Sigurgeirsson B for the LION study group. Double blind, randomised study of continuous terbinafine compared with intermittent itraconazole in treatment of toenail onychomycosis. BMJ 1999;318:1031-5. (17 April.) 2 Epstein E. How often does oral treatment of toenail onychomycosis produce a disease-free nail? An analysis of published data. Arch Dermatol 1998;134:1551-4.

Prescribing terbinafine to every patient with the condition would be expensive

EDITOR-The paper by Evans and Sigurgeirsson raises two issues about the treatment of toenail onychomycosis.

Firstly, a follow up time of 72 weeks may not be a true measure of effectiveness of treatment. Our experience in primary care is that many patients are found to have been put into remission rather than cured when followed up over longer periods.

Secondly, terbinafine for toenail onychomycosis is usually prescribed by general practitioners. A more important issue for primary care is which patients actually require treatment. In 1996, terbinafine appeared in our PACT (prescribing analysis and cost) data among the 20 most expensive drugs, reaching number 12 at its high point. The drug was widely advertised, and patients consulted us, often on the advice of their chiropodist (chiropodists are unable to prescribe it), asking for a prescription. Most of these patients had a purely cosmetic problem.

We consulted the local dermatology and podiatry departments and pharmaceutical adviser. The consensus was that treatment of toenail onychomycosis was necessary only if the infection was contributing to a biomechanical foot problem or if the patient also had neurological or circulatory problems. As a result we now explain to patients that they do not need treatment if the problem is purely cosmetic; most accept this. If treatment is indicated it is now started only after microbiological confirmation of infection. This policy has reduced our prescription rate to three courses of treatment over 12 months, compared with nine prescriptions over three months in 1996.

We cannot identify any trials in the literature with follow up for longer than 72 weeks. We think that trials over three to five years should be undertaken before it is claimed that terbinafine is both an effective and a cost effective treatment. The current cost to the NHS of each patient with microbiological cure at 72 weeks is £256. If our 1996 level of 18 courses of treatment per general practitioner per year were repeated across the United Kingdom the costs would be staggering.

Peter Rose general practitioner

Tim Wilson general practitioner

Mill Stream Surgery, Benson, Oxfordshire

OX10 6RL

Peter.Rose@public-health.oxford.ac.uk

Competing interests: None declared.

1 Evans EGV, Sigurgeirsson B for the LION study group. Double blind, randomised study of continuous terbinafine compared with intermittent itraconazole in treatment of compared with intermittent itraconazole in treatment of
toenail onychomycosis. BMJ 1999;318:1031-5. (17 April.)

\section{Do crinkly toenails really matter?}

EDITOR-The methodology of Evans and Sigurgeirsson's paper on the treatment of toenail infections was thorough, and the con- clusions were generally sound, ${ }^{1}$ but does this warrant its being published in the BMJ? I am a general practitioner and cannot dream of using terbinafine or itraconazole for my patients, however well they work. Where were the arguments about the importance of the problem or the justification for treating it? I am surprised that the $B M J$, usually so down to earth, should ignore these points.

If $2-4 \%$ of my 5000 patients have onychomycosis it would cost $£ 17864$ to $£ 35728$ to treat them according to these findings. For that I could save two to five lives by implementing the Sheffield tables for lipid lowering treatment for the primary prevention of coronary heart disease,,$^{2}$ or do a hundred other things.

The senior authors declare a conflict of interest, saying that they are both closely linked to the company that makes the drug they favour. How about the $B M J-$ do all the staff have crinkly toenails?

Jessica Harris general practitioner

Bacon Road Medical Practice, Norwich NR2 3QX baconrd@aol.com

Competing interests: None declared.

1 Evans EGV, Sigurgeirsson B for the LION study group. Double blind, randomised study of continuous terbinafine compared with intermittent itraconazole in treatment of toenail onychomycosis. BMJ 1999:318:1031-5. (17 April) toenail onychomycosis. BMJ 1999;318:1031-5. (17 April.)
2 Ramsay LE, Wallis EJ, Haq IU, Jackson PR, Yeo WW. Policy 2 Ramsay LE, Wallis EJ, Haq IU, Jackson PR, Yeo WW. Policy 1999;318:1140-1. (24 April.)

\section{Author's reply}

EDITOR-The study is important because it shows which of two commonly prescribed antifungals agents is most effective in onychomycosis. The criticism that one of the manufacturers financed the study is naive. No single centre could feasibly be expected to recruit the numbers of patients (496) in this study within a reasonable time. The study was conducted to the highest clinical trial standards, and those who paid for it could not influence the results.

That only half of the patients showed complete cure of the nails does not mean that fungal nail disease is incurable. The fact that the nails were not completely normal in half of cases by the strict study criteria may be misleading as in many cases the nails may not have been completely normal to start with. In the patient global assessment $79 \%$ of patients who took terbinafine were happy with their nails at the end of the study.

How long the follow up should be in studies in onychomycosis is often debated. This study has the longest follow up of any published antifungal trial in nails. It takes about 12-18 months for toenails to be replaced, so a 72 week study is appropriate to assess efficacy. After this it is difficult to distinguish relapse from reinfection.

Most study patients had severe onychomycosis, which reflected the profile of patients seeking treatment, so the results are likely to be valid. We could have been criticised if patients were confined to those with predominantly mild or moderate disease.

Obviously, cost issues are important, but onychomycosis cannot be regarded as just a cosmetic problem. If left untreated the disease in individual nails will progress relentlessly and potentially will destroy the whole nail completely. Untreated nails act as a fungal reservoir, allowing infection to spread to other nails and skin and to other people. It may not be wise to delay treatment, because older patients may have peripheral vascular disease and the diminished blood supply will make treatment of their onychomycosis more difficult. Early treatment also helps prevent secondary complications-for example, cellulitis of the leg-that are likely to be more costly to treat than the onychomycosis.

Finally, nails serve several important physical functions. Onychomycosis has been shown to affect quality of life in terms of self esteem and interfering with patients' occupations.

E G V Evans professor of medical mycology

University of Leeds, Leeds LS2 9JTY

E.G.V.Evans@leeds.ac.uk

Professor Evans has received funds for research and attending symposia and also fees for speaking and consulting from a number of pharmaceutical companies, including Novartis Pharma and Janssen Pharmaceuticals.

1 Scher RK. Onychomycosis is more than a cosmetic problem. BrJ Dermatol 1994;130(suppl 43):15.

\section{Roughly quarter of $B M J$ staff surveyed said they had crinkly toenails}

EDITOR-We tried to answer this important question-how many $B M J$ staff had crinkly toenails-by using a simple questionnaire, which was distributed to 30 available members of the BMJ editorial office. The response rate was $77 \%(\mathrm{n}=23)$ and the median age 42 (range 25-67). Two of the participants did not know what crinkly toenails were; six of the remaining 21 reported that they had crinkly toenails, of whom two had actually treated them and another two had thought about treating them.

In conclusion, about a quarter of the $B M J$ staff has crinkly toenails and it seems to matter to those affected. Of course, there are several severe limitations to this small survey. The particular setting implies certain selection criteria for all participants, and generalisability is questionable. Misclassification cannot be ruled out, as the presence of crinkly toenails is self reported. In this particular situation, however, we would expect underreporting and thus the magnitude of the problem to be even bigger.

Marcus Müllner acting letters editor $B M J$, London WC1H 9JR

\section{CT scanning can differentiate between ischaemic attack and haemorrhage}

EDITOR-I am concerned about Gunatilake's reports of cases in which rapid resolution of intracerebral haemorrhage occurred. ${ }^{1}$ The author's premise is founded on two erroneous statements. Gunatilake stated that "no one has reported resolution of the symptoms and signs of intracerebral haemorrhage within 24 hours, although the 
Results of computed tomography in patients with clinical diagnosis of transient ischaemic attack in Split, Croatia, 1991-7

\begin{tabular}{lc} 
Diagnosis & $\begin{array}{c}\text { No }(\%) \\
(\mathbf{n}=\mathbf{1 3 4 )}\end{array}$ \\
\hline Normal findings & $103(77)$ \\
\hline Cerebral infarction & $19(14)$ \\
\hline Cerebral tumour & $7(5)$ \\
\hline Cerebral parasites & $2(2)$ \\
\hline Subdural haematoma & $2(2)$ \\
\hline Cerebral haemorrhage & $1(0.7)$ \\
\hline
\end{tabular}

possibility has been recognised." The author obviously chose to ignore published data that showed a rapid resolution of neurological deficit after intracerebral haemorrhage..$^{2-4}$

Gunatilake also stated: "Intracerebral haemorrhage ... is not included in the differential diagnosis of transient ischaemic attacks." In his work on vascular diseases of the central nervous system Ross Russell states: "With CT scanning it is now possible to be sure that a brief reversible focal disturbance is not due to a minor haemorrhage or to a cerebral tumour., ${ }^{5} \mathrm{He}$ emphasises this statement with a diagnostic algorithm, which includes using computed tomography to differentiate between ischaemia and haemorrhage.

Transient ischaemic attacks are agreed to be episodes of focal neurological deficit in a vascular distribution. They have been seen as a marker for the risk of cerebral infarction. This opinion has persisted despite the introduction of new diagnostic methods such as computed tomography, magnetic resonance imaging, and positron emission tomography. These methods have shown that even in people with normal findings on neurological examination there were often prolonged morphological, physiological, or metabolic disturbances. Therefore, the question is: should we classify these patients as having a transient ischaemic attack (on the basis of their history and the absence of neurological signs and symptoms) or as having a cerebral infarction (on the basis of neuroimaging)? Additionally, the unexpected frequency with which other causative factors-which imitate a transient ischaemic attack-are identified using the new neuroimaging techniques has created a need to redefine the differential diagnosis of transient ischaemic attacks.

In an investigation carried out between 1991 and 1997 my colleagues and I identified 134 patients who had had a transient ischaemic attack and who were admitted on an emergency basis. Although we tried to use strict criteria, after undergoing computed tomography, 23\% of patients were found to be misclassified (table).

Lušić Ivo neurologist

Department of Neurology, Clinical Hospital Split, Spinčićeva 1,21000 Split, Croatia ivo.lusic@st.tel.hr

Funding: The study described was funded by the Croatian Ministry of Science (project No. 3-01-229).

1 Gunatilake SB. Rapid resolution of symptoms and signs of intracerebral haemorrhage: case reports. BMJ 1998;316: 1495-6. (16 Mav)
2 Chen WH, Lin JS, Wu SC, Chang YY. Transient global amnesia and thalamic hemorrhage. Clin Neurol Neurosurg 1996;98:309-1

3 Aparicio A, Sobrino J, Arboix A, Torres M. Hematoma intraparenquimatoso que simula un accidente isquemico transitorio. Medicina Clinica 1995;104:478-9.

4 Sohn YH, Kim SM, Kim JS, Kim DI. Benign brainstem hemorrhage simulating transient ischemic attack. Yonse Med J 1991;32:91-3.

5 Ross Russell RW Transient cerebral ischaemia In: Vasculer disease of the central nervous systen. Edion. Chuthill Livingstone, 1983:205-23.

\section{Getting letters published in journals is good aim for medical students}

EDITOR-The increasing emphasis on evidence based medicine in the NHS means that skills in critical appraisal will soon be as important for doctors as clinical competence. Many habits are established at medical school, so encouragement for students to review and publish work should start there. It is our impression that such motivation and support are patchy. To investigate this, we examined letters to the $B M$ J over three years and quantified the extent of medical student authorship. Authors often begin their careers by writing letters, and letters can be a marker of competence in critical appraisal. We chose the $B M J$ because it has a substantial student readership.

We examined the letters sections of the BMJ from July 1996 to June 1999 (volumes 314-319) and recorded the total number of letters and the number with at least one medical student author. Medical students' letters were categorised into four types: author's reply; critical appraisal of a published paper; original work, which included case reports, case series, and other results of research; and viewpoint, which offered an opinion on any topic or article but without critical appraisal of the work.

Twenty six $(0.7 \%)$ of the 3842 published letters had at least one medical student author (table). Medical students from the University of Newcastle upon Tyne contributed six of the 21 letters from medical students in the United Kingdom (29\%; 95\% confidence interval $11 \%$ to $52 \%$ ). All of the Newcastle letters were critical appraisals

from fourth year students of epidemiology and public health and were written without coauthors. Four of the remaining 20 letters were from medical students writing alone. Coauthors were drawn from psychiatry (five letters); medicine (five); surgery (three); and pathology, general practice, neuroradiology, and medical laboratory science (one each). Two coauthors were in unspecified research posts, and one was a hospital director.

The performance of the Newcastle students presents a challenge to others involved in training. The assessment of teaching quality in universities is in its infancy, and a department's ability to motivate students will be hard to quantify. We believe that publication of critical appraisal letters by medical students has merit as an informal measure. As well as showing a skill that all doctors need, these letters are likely to stimulate interest in research and academic medicine. Setting out early on the quality spiral of publishing may help to raise standards. Perhaps we should consider replicating Newcastle's example across the United Kingdom.

Barbara Hanratty visiting lecturer in public health medicine

Debbie Lawlor visiting lecturer in public health medicine

Nuffield Institute for Health, Leeds LS2 9PL

hssbh@leeds.ac.uk

\section{In general practice Scottish NHS and English NHS differ considerably}

EDITOR-Dixon et al's observations about the numbers and workloads of general practitioners scarcely accord with data in their tables. ${ }^{1}$ Few English general practitioners would agree that "there were small differences in the numbers of hospital doctors and general practitioners (table 3)" in the four home countries, since the staffing of unrestricted principals per 1000 population is shown in that table as $40 \%$ higher in Scotland than in England. Although the paper acknowledged that the crude workload was

Number of letters from medical students published in BMJ, by university or hospital medical school

\begin{tabular}{|c|c|c|c|c|}
\hline \multirow[b]{2}{*}{ University or hospital medical school } & \multirow[b]{2}{*}{ No of letters } & \multicolumn{3}{|c|}{ Category of letter* } \\
\hline & & $\mathrm{CA}$ & $\mathbf{O R}$ & V \\
\hline Aberdeen & 1 & - & - & 1 \\
\hline Dundee & 1 & - & - & 1 \\
\hline Edinburgh & 2 & $1 \dagger$ & $2 \dagger$ & - \\
\hline King's College, London & 1 & - & - & 1 \\
\hline Leicester & 1 & 1 & - & - \\
\hline Manchester & 1 & $1 \dagger$ & $1 \dagger$ & - \\
\hline Newcastle upon Tyne & 6 & 6 & - & - \\
\hline Oxford & 3 & $2 \dagger$ & $1 \dagger$ & 1 \\
\hline Sheffield & 1 & $1 \dagger$ & $1 \dagger$ & - \\
\hline St Bartholomew's, London & 1 & $1 \dagger$ & $1 \dagger$ & - \\
\hline St Mary's, London & 2 & - & - & 1 \\
\hline UK unknown & 1 & - & - & 1 \\
\hline Overseas & 5 & 3 & 2 & - \\
\hline
\end{tabular}

${ }^{*} \mathrm{CA}=$ critical appraisal of published paper; $\mathrm{OR}=$ original work; $\mathrm{V}=$ viewpoint. No letters were identified as author's replies.

†Letters that covered more than one category. 
lower in Scotland than in England, the figures for mean consultations per person reflect 9400 consultations a year per general practitioner in England, a figure 26\% greater than the 7425 consultations in Scotland. These are considerable differences.

General practitioners practising in England know that the reality differs from that perceived by the authors. Assertions from prominent academic institutions can be believed by central planners without their needing to scrutinise the data. A misleading comment about simple data is unhelpful, especially at a time when general practitioners are having to effect the latest administrative changes with essential criteria that are not yet fully defined.

Stephen Bamber general practitioner

Long Stratton, Norfolk NR15 2TS

Dixon J, Inglis S, Klein R. Is the English NHS underfunded? BMJ 1999;318:522-6. (20 February.)

\section{Study confirms tendency towards lower risk of myocardial infarction with second generation oral contraceptives in UK}

EDITOR-Lidegaard is mistaken in his commentary on the MICA study of oral contraceptives and myocardial infarction. ${ }^{1}$ Third generation oral contraceptives were, in fact, preferentially prescribed to women at lower risk of myocardial infarction. The odds ratios of third versus second generation pills increased rather than decreased when more potential confounders were entered into the logistic model. ${ }^{1}$ Similar preferential prescribing in favour of third generation contraceptives was found in the only empirical study of prescribing in the United Kingdom. ${ }^{2}$

The MICA study should now lay to rest the lipid hypothesis of oral contraceptives and myocardial infarction, which was influential in the massive shift in prescribing to third generation pills (which have less effect on blood lipid concentrations) in the early 1990s. Angiography after myocardial infarction has shown that oral contraceptive users have little atherosclerosis, which is consistent with repeated epidemiological findings that past use of oral contraceptives does not affect risk of infarction. These findings should preclude a lipid effect.

The other main study comparing second and third generation pills, the transnational study, also found a tendency towards lower risk with second generation oral contraceptives in the United Kingdom. ${ }^{3}$ A higher risk with second generation pills was found only in continental Europe. However, $55 \%$ of women there did not have their blood pressure measured before starting the pill ( $17 \%$ in the United Kingdom), and blood pressure was measured less frequently in users of second generation contraceptives (M A Lewis, personal communication). The apparent increased risk with second generation pills was probably due to inadequate screening for hypertension in older women taking these pills. The World Health Organisation study found no difference in risk between the generations after controlling for measurement of blood pressure.

Lidegaard et al, who have argued that for most women the balance in terms of cardiovascular safety lies with third generation contraceptives ${ }^{5}-\mathrm{a}$ view widely promoted in the past few years-now need to reassess this advice in the light of the MICA study. There seems to be no reduction in risk of myocardial infarction with third generation contraceptives to compensate for the increased risk of venous thromboembolism, a risk recently restated by the United Kingdom's Medicines Control Agency.

The remaining question about third generation oral contraceptives is whether there is any benefit from these pills with lower androgenicity on the minor but important symptoms of acne or breakthrough bleeding. We await a Cochrane Collaboration review that should provide the answers.

Paul O'Brien senior clinical medical officer in clinical effectiveness

Services for Women, Parkside Health NHS Trust, St Charles Hospital, London W10 6DZ PaulOBrien@care.prestel.co.uk

Dr O'Brien has provided advice to the legal team representing women who developed a venous thrombosis while taking third generation oral contraceptives. He has been paid for this work.

1 Dunn N, Thorogood M, Faragher B, de Caestecker L, MacDonald TM, McCollum C, et al. Oral contraceptives and Donald TM, MeCollm C, et al. Ora concace myocardial infarction: results of the MICA case-contro study. [With commentary 1999;318:1579-84. (12 June)

2 Dunn N, White I, Freemantle S, Mann R. The role of prescribing and referral bias in studies of the associatio between third generation oral contraceptives an ncreased risk of thromboembolism. Pharmacoepidemiol Drug Safety 1998;7:3-14.

3 Lewis MA, Heinemann LA, Spitzer WO, MacRae KD, Bruppacher R. The use of oral contraceptives and the occurrence of acute myocardial infarction in youn women. Results from the transnational study on oral contraceptives and the health of young women. Contraception 1997;56:129-40

4 World Health Organisation Collaborative Study of Cardiovascular Disease and Steroid Hormone Contraceptionascular Disease and Stion Acute myocardial infarction and combicd oral contraceptives. Lidegaard O, Bygdeman M, Milsom I, Nesh estad FE, Toivonen J. Oral contraceptives and thrombosis. rom risk estimates to health impact. Acta Obstet Gynecol Scand 1999;78:142-9.

\section{Numbers needed to treat derived from meta-analysis}

\section{Are an absurdity}

EDIToR-Better late than never. Several years ago one group of epidemiologists put forward the number needed to treat (NNT) derived from megatrials and meta-analysis as a summary statistic suitable for expressing the effectiveness of medical interventions; now another group of epidemiologists has at long last realised that the NNT is seldom a

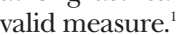

Some of us came to the conclusion that NNTs were "not necessarily true" rather more rapidly, and without the need for three and a half pages of cumbersome and dubiously appropriate statistical analysis.
The deep flaws in the NNT statistic can be understood by a straightforward act of inference based on an understanding of the relevant clinical science and guided by the principle of "garbage in, garbage out."

The spurious precision of the NNT is a statistical artefact which derives not from clinical knowledge but from the illegitimate pooling of the large amounts of qualitatively unlike and clinically irrelevant data that are incorporated in almost all megatrials and meta-analyses. Unless trials incorporate patients with the same characteristics and the same prognosis and who are being given the same treatment as those to which the trial results will apply, then statistical summary is inevitably misleading. ${ }^{2}$

It is somewhat galling that megaepidemiologists and biostatisticians so routinely take credit for the act of creating spurious analytic tools, and then for belatedly dismantling them-but so it goes. The wheels of epidemiology grind exceedingly slow. At least Smeeth et al got there in the end.

When clinical epidemiology gives up its grandiose and self awarded claim to be "evidence-based medicine" and once again becomes an activity based in clinical science, such absurdities may become a thing of the past. I hope so.

Bruce G Charlton lecturer

Department of Psychology, University of Newcastle upon Tyne, Newcastle upon Tyne NE1 7RU Bruce.Charlton@newcastle.ac.uk

1 Smeeth L, Haines A, Ebrahim S. Numbers needed to trea derived from meta-analysis-sometimes informative, usually misleading. $B M J$ 1999;318:1548-51. (5 June.)

2 Charlton BG. The future of clinical research: from megatrials towards methodological rigour and representative sampling. J Eval Clin Pract 1996;2:159-69.

\section{Using patient years may also be misleading}

Editor-Smeeth et al showed how inappropriate methods of calculating numbers needed to treat (NNTs) in systematic meta-analyses can be misleading. ${ }^{1}$ The examples they chose quoted event rates in patient years. Smeeth et al calculated (correctly in our view) their NNTs directly from the events per patient year. However, some commentators on such trials quote NNTs for the average follow up period of the trial. This alternative method may be considered acceptable, even though it is only an approximation to the first method, but we would draw attention to how misleading failure to recognise the difference between the two methods can be.

In the UKPDS 38 trial, $^{2}$ for example, method 1 would give an NNT to prevent any diabetic related death as 152 patients per year, or 15.2 patients over 10 years. Method 2 would give an NNT of 20 over 8.4 years (the median follow up). The three choices of NNT, $152,15.2$, or 20 , can lead to misunderstanding. That this is a real problem was illustrated in an electronic response regarding the UKPDS 38 trial: "We are concerned that there is a discrepancy between the numbers needed to treat which are stated in the article, and those that can be calculated. The study states that the number needed to 
treat over 10 years to prevent any complication is 6.1 and to prevent death from a diabetes related cause is 15.0. In calculating the numbers needed to treat by using the values in figure 4 (based upon a median follow up of 8.4 years), we conclude that the number needed to treat to prevent any complication is 11, and to prevent death is 20."'

At our local critical appraisal seminars for general practitioners in Suffolk, we encountered similar confusion when two participants presented NNTs from the HOT trial. ${ }^{4}$ An added twist to the potential for comparisons appears when some trials report the average follow up period as a mean (the HOT trial) while others report the median (UKPDS 38).

There is a case for standardising the way NNTs are reported for trials which give their results in the form of events per patient years-or at least insisting that commentaries make clear which method they are using.

An fuller explanation of the different methods can be viewed on www.suffolkmaag.ac.uk/ebm/pt-yrs\&NNTs.html, with examples available for the UKPDS 38 trial (www.suffolk-maag.ac.uk/stats/cpukpds.html) and for the HOT trial (www.suffolkmaag.ac.uk/stats/cphot.html).

Kevork Hopayian general practitioner

The Surgery, Leiston, Suffolk IP16 4ES

k.hopayian@tesco.net

John McGough general practitioner

The Surgery, Aldeburgh, Suffolk

1 Smeeth L, Haines A, Ebrahim S. Numbers needed to treat derived from meta-analyses sometimes informative, usually misleading. $B M J$ 1999;318:1548-51. (5 June.)

2 UK Prospective Diabetes Study Group. Tight blood pressure control and risk of macrovascular and microvascular complications in type 2 diabetes. BMJ 1998.317: 703-13.

3 Electronic responses. Tight blood pressure control and risk of finacrovascular and microvascular complications in type 2 (1999).

uthers SG, Dahlöf B, Elmfeldt D, Julius S, et al. Effects of intensive bloodpressure lowering and low dose aspirin with hypertension: principal results of the hypertension optimal treatmen (HOT) randomised trial. Lancet 1998;351:1755-62.

\section{Length of follow up is poorly reported}

EDITOR-Smeeth et al raise interesting issues concerning the validity of reporting numbers needed to treat (NNTs) in systematic reviews that combine trials with varying periods of follow up. ${ }^{1}$ In such situations, only when the absolute treatment effect is constant over time can the NNT be correctly estimated from the reciprocal of the pooled absolute risk difference. By contrast, if a treatment has a constant relative effect over time, then within a single trial the NNT will decrease with increasing follow up. ${ }^{2}$ Similarly, we expect that the NNT will also vary among several similar trials with different lengths of follow up.

The reporting of length of follow up is often inadequate to assess whether the constant absolute risk model or constant relative risk model is the more appropriate in a given systematic review, or to make adjustments for length of follow up in the analysis. We assessed the quality of reporting of length of follow up in the systematic reviews published in the Cochrane Library (Issue 1,
1998) that synthesised mortality outcomes. We excluded reviews in pregnancy and childbirth, where duration of follow up is typically not an issue. The 44 relevant systematic reviews that we found combined 306 trials. For $43 \%$ of the trials there was no mention of the duration of follow up in the published review.

To assess whether the cause was inadequate trial reporting or poor data abstraction we considered in more detail the 17 systematic reviews for interventions related to stroke, and compared the reporting of follow up in the reviews with that in the 103 trials on which they were based. We noted whether the reviewers had categorised the length of follow up as fixed (all participants studied for the same length of time) or variable (follow up summarised by mean, median, or range) or whether follow up was not stated. We found 93\% agreement between the reviewers' abstractions and our own assessments, which suggests that poor reporting of trials is responsible for many of the omissions. These results support the results of other reviews of reporting of follow up in clinical trials and cohort studies. ${ }^{34}$

Our findings suggest that, as so many trial reports omit mentioning length of follow up, in practice it may not be possible to adjust for length of follow up in a systematic review.

Roberto D'Amico medical statistician r.d'amico@icrf.icnet.uk

Jonathan J Deeks medical statistician Douglas G Altman professor of statistics in medicine ICRF/NHS Centre for Statistics in Medicine, Institute of Health Sciences, Oxford OX3 7LF

We are grateful for the assistance of Hazel Fraser and the Cochrane Stroke Review group for allowing us access to copies of the 103 trials.

1 Smeeth L, Haines A, Ebrahim S. Numbers needed to trea derived from meta-analyses-sometimes informative, usually misleading. BMJ 1999;318:1548-51. (5 June.)

2 Altman DG, Andersen PK. Calculating the number needed to treat for trials where the outcome is time to an event. $B M J$ (in press).

3 Altman DG, De Stavola BL, Love SB, Stepniewska KA Review of survival analyses published in cancer journals. Br J Cancer 1995;72:511-8.

Schemper M, Smith TL A note on quantifying follow-up Scher M, Smith TL. A note on quantifying follow-up in studies of failure time. Controlled Clinical Trials 1996

\section{NNT is a tool, to be used appropriately}

EDITOR-There is much to agree with in the article on numbers needed to treat (NNT) by Smeeth et al. ${ }^{1}$ But to use the word misleading in the title is in itself misleading. NNTs are a huge advance on what we had before. Smeeth et al point out, as has been done previously, that for NNTs to be comparable they must define patients' condition and severity, the intervention, outcome, and duration, ${ }^{2}$ and perhaps other relevant issues. In saying that NNTs should reflect underlying baseline risk for an individual patient (or group of patients) they are restating a method described by Sackett et al. ${ }^{3}$

The problem with their argument is that it is derived from examples of interventions used to prevent small effects in large numbers of patients. Most of us live in a medical world where we need interventions that produce large effects in small populations. In these circumstances, NNTs from meta-analysis are usually informative and seldom misleading.

Take acute pain as an example. Many high quality randomised, double blind, and placebo controlled clinical trials have been done over 50 years. For trials to be clinically valid patients have to have moderate or severe pain on entry. Pain is measured with standard scales over periods of 4-6 hours Using the outcome of relief of at least half the pain over this time we have been able to calculate NNTs compared with placebo for a range of analgesic interventions (references on the $B M J \mathrm{~s}$ website). NNTs are unaffected by pain model (dental or postoperative), pain measurement, duration (four or six hours), or reporting quality (given that trials are randomised and double blind). ${ }^{4}$

Moreover, we have been able to use large amounts of data from individual patients and clinical trials to investigate the effect of chance on baseline and experimental event rates. ${ }^{5}$ Because individual clinical trials are set up to investigate the direction of treatment effect (treatment better than control), we need to know how much information is needed to overcome random effects in estimating the magnitude of the clinical effect of an intervention-or when an NNT becomes clinically valid. ${ }^{5}$

NNT is a tool. Like any tool, when used appropriately it will be helpful and effective. What we have to do is to ensure that in any given situation we know what the rules are for using the tools correctly. Making swingeing oversimplifications from the same selected trials doesn't move us any further forward.

Andrew Moore consultant biochemist andrew.moore@pru.ox.ac.uk

Henry McOuay clinical reader in pain relief Pain Research, Churchill, Oxford OX3 7LJ

1 Smeeth L, Haines A, Ebrahim S. Numbers needed to treat derived from meta-analyses - sometimes informative, usually misleading. BMJ 1999:318:1548-51. (5 June.)

2 McQuay $\mathrm{H}, \mathrm{M}$ McQuay HJ, Moore RA. Using numerical results from systematic reviews in clinical practice. Ann Intern Med
1997;126:712-20. 3 Sackett DL, Richardson WS, Rosenberg W, Haynes RB. Evidence-based medicine: how to practice and teach EBM. New York: Churchill Livingstone, 1997:168-71

4 Edwards JE, Oldman A, Smith L, Wiffen PJ, Carroll D, McQuay HJ, Moore RA. Oral aspirin in postoperative pain: a quantitative systematic review. Pain (in press).

5 Moore RA, Gavaghan D, Tramèr MR, Collins SL, McQuay HJ. Size is everything-large amounts of information are needed to overcome random effects in estimating direction and magnitude of treatment effects. Pain 1998:78:209-16.

\section{Cholesterol lowering margarine is effective}

EditoR-Van Heyningen suggests that a margarine containing plant stanol ester (Benecol) may not lower low density lipoprotein cholesterol concentration in people with a fat modified diet. ${ }^{1} \mathrm{He}$ presents no evidence of his own for this assertion but cites a study by Denke in which participants were given plant stanol in gelatin capsules. ${ }^{2}$ 
However, he fails to cite a more recent study in which plant stanol esters were dissolved in margarine and fed to participants eating a diet which provided only $26 \%$ of energy as fat and about $150 \mathrm{mg}$ of cholesterol daily. Reductions in low density lipoprotein cholesterol concentration in the two test groups were $8.6 \%$ and $13.7 \%$ respectively compared with controls. In another recent study of subjects on a prudent diet, plant stanol dissolved in margarine lowered low density lipoprotein cholesterol by $15.5 \%$ more than did margarine without plant stanol. ${ }^{4}$

As pointed out by Jones et al, ${ }^{4}$ Denke's negative results probably reflect the fact that she administered plant stanol in capsules, which presumably impaired its ability to inhibit cholesterol absorption in the small intestine, rather than the effect of a fat modified diet. Such a diet has been shown to accentuate the extent to which low density lipoprotein cholesterol concentration is lowered by Benecol.

\section{Gilbert R Thompson emeritus professor of clinical} lipidology

Metabolic Medicine, Division of Investigative Science, Imperial College School of Medicine Hammersmith Hospital, London W12 0NN gthompso@rpms.ac.uk

GRT is a part time medical consultant to McNeil Consumer Nutritionals, distributors of Benecol products in Europe.

1 Van Heyningen C. Cholesterol lowering margarine may not be useful in healthy fat modified diet. BMJ not be useful in he

2 Denke MA. Lack of efficacy of low dose sitostanol therapy as an adjunct to a cholesterol-lowering diet in men with moderate hypercholesterolemia. Am J Clin Nut 1995;61:392-6.

3 Hallikainen MA, Uusitupa MI. Effects of 2 low-fat stano ester-containing margarines on serum cholesterol concentrations as part of a low-fat diet in hypercholesterolemic subjects Am J Clin Nutr 1999;69:403-10.

4 Jones PJ, Ntanios FY, Raeini-Sarjaz M, Vanstone CA Cholesterol-lowering efficacy of a sitostanol-containing phytosterol mixture with a prudent diet in hyperlipidemic men. Am J Clin Nutr 1999;69:1144-50.

5 Vessby B. Lipid-lowering effects of a stanol estercontaining margarine when used as part of a strictly controlled lipid-lowering diet. Eur Heart J (suppl) (in press).

\section{Trends in emergency admissions}

\section{Shop floor experience suggests a rise}

EDITOR-Morgan et al report that they find little evidence for a rise in emergency admissions from NHS data returns. ${ }^{1}$ Their conclusion is that much of the increase in admissions is due to internal transfer between consultants generating multiple finished consultant episodes for an individual patient's admission. My memory suggests that this was a prediction raised in letters to the $B M J$ when the finished consulting episode first became a recognised measure of hospital activity.

In accident and emergency our level of information technology is often more basic and our workload is dependent on the number of people passing through the department. I have simple number data for the accident and emergency departments that I have worked in during the period in
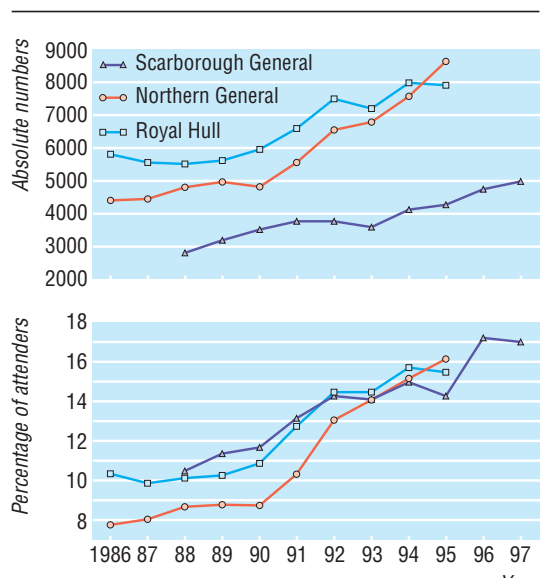

Numbers of patients admitted from accident and emergency in three hospitals, 1986-97: absolute numbers (top) and percentage of all attenders (bottom)

question (figure). In two departments there has been an $85 \%$ increase in the number of patients admitted. The percentage of patients admitted from the total seen in the departments has risen in all from $11 \%$ in the late 1980 s to $17 \%$ in the late $1990 \mathrm{~s}$.

From the accident and emergency medicine view, more patients are attending the departments and more of these patients are admitted despite, or perhaps because of, an increase in the seniority of the doctors who receive them. During this period the specialty of accident and emergency medicine has matured, with the expansion of training schemes, an increase in the number of consultants, and the development of its own faculty.

If official statistics do not show the trends seen by the simple counting of patients through a department, where does the discrepancy lie? Are we on the shop floor incorrect in our assessment of the workload, or does the processing of the data returned from our departments somehow lose the message contained?

Andrew Volans consultant in accident and emergency medicine

Scarborough Hospital, Scarborough YO12 6QL

1 Morgan K, Prothero D, Frankel S. The rise in emergency admissions-crisis or artefact? Temporal analysis of health services data. BMJ 1999;319:158-9. (17 July.)

\section{Rise has been real in Glasgow}

EDITOR-Morgan et al conclude that the rise in emergency admissions is an artefact that is almost entirely attributable to the increased reporting of internal transfers of patients after admission. ${ }^{1}$ They suggest that extrapolation from Kendrick's Scottish data up to 1994 is seriously misleading for the interpretation of more recent trends. ${ }^{2}$ Kendrick showed that in Scotland surgical emergency admissions were almost static. ${ }^{2}$ However, Morgan et al considered both medical and surgical emergency admissions, which may partially explain the lower rise they describe.
The Scottish morbidity record (SMR01) system differentiates between admissions and internal transfers. We re-examined recent data for adult emergency medical admissions in Glasgow. ${ }^{3}$ Admissions rose by a mean of 3.9\% a year between 1994 and 1997 compared with a mean annual rise of $4.4 \%$ for the years 1980 to 1994 after internal transfers were excluded.

This confirms that the rise in emergency admissions reported by Kendrick is a continuing trend. In Glasgow, unlike Avon, the rise in emergency medical admissions has been real, not an artefact.

Oliver Blatchford research fellow oblatchford@bigfoot.com

Simon Capewell senior lecturer

Department of Public Health, University of Glasgow, Glasgow G12 8RZ

Mary Blatchford senior clinical tutor Department of General Practice, University of Glasgow, Glasgow G12 ORR

1 Morgan K, Prothero D, Frankel S. The rise in emergency admissions-crisis or artefact? Temporal analysis of health service data. $B M J$ 1999;319:158-9. (17 July.)

2 Kendrick S. The pattern of increase in emergency hospital admissions in Scotland. Health Bull (Edinb) 1996;54(2): 169-83.

3 Blatchford O, Capewell S, Murray S, Blatchford M. Emergency medical admissions in Glasgow: general practices vary despite adjustment for age, sex and deprivation. BrJ Gen Pract 1999;444:551-4.

\section{Effect of supplementation with vitamin $A$ or $\beta$ carotene on mortality related to pregnancy}

\section{Pooling of groups may not be appropriate}

EDITOR-West et al reported that vitamin A and $\beta$ carotene reduced mortality related to pregnancy up to 12 weeks post partum, ${ }^{1}$ but the conclusions cannot be considered to be unequivocal. Any differentials in ascertainment of pregnancies in the different groups could vitiate the results. About 6-7\% of the pregnancies ended as miscarriages and stillbirths, and 2\% had no reported outcome. Were there any differences between the groups in this outcome? If the 157 women were lost to follow up because they had died it would spuriously decrease mortality in the vitamin A group compared with the placebo group.

Although only half the women received $\geqslant 80 \%$ of the intended quantity of vitamin A or $\beta$ carotene supplements, mortality was reduced substantially (40-50\%). The authors report that the evidence of survival was noticed after 1.5 years of the trial, indicating a cumulative effect of supplementation, which depends on duration of feeding. Thus the women participating for shorter periods would have consumed lower amounts than those participating for longer periods even if they had consumed the intended quantities. In the absence of data on the relation between the total dose and maternal mortality, the authors' contention that "the risk of maternal death in vitamin A deficient populations could be substantially lowered with modest increase in vitamin $\mathrm{A}$ or $\beta$ carotene intake" is hypothetical. 
Several relative risks were not significantly different when tested separately for the vitamin $A$ or $\beta$ carotene groups but were significant when the groups were pooled. Is the significance spurious because of the increase in numbers due to pooling? protection from death due to injuries and other miscellaneous causes not attributable to it. The recalculated relative risks, excluding the deaths due to injuries, were significantly different in the $\beta$ carotene group $(0.523 ; 95 \%$ confidence interval 0.44 to 1.07 ) but not the vitamin A group (0.689; 0.32 to 0.86 ). Interestingly, the increase in serum retinol concentrations in these two groups was comparable. The proportions of pregnant women with serum retinol $<0.7$ $\mathrm{mmol} / \mathrm{l}$ in the $\beta$ carotene and placebo groups were comparable, although significantly different $(\mathrm{P}<0.001)$ from the proportion in the vitamin A group in both cases. The serum $\beta$ carotene concentrations, although higher in the $\beta$ carotene group, were not different between the placebo and vitamin A groups. Therefore it may not be appropriate to pool the groups.

The study thus seems to raise more questions than it answers. These require clarification before claims are made that vitamin $\mathrm{A}$ and $\beta$ carotene reduce mortality in women due to pregnancy by as much as $40-50 \%$

K Vijayaraghavan senior deputy director Kamala Krishnaswamy director

National Institute of Nutrition, Jamai-Osmania, Hyderabad, 500 007, India

icmrnin@ren.nic.in

1 West KP Jr, Katz J, Khatry SK, LeClerq SC, Pradhan EK, Shreshta SR, et al. Double blind, cluster randomised trial of low dose supplementation with vitamin A or $\beta$ carotene on mortality related to pregnancy in Nepal. BMJ 1999;318:

\section{No magic pills exist for reducing mortality related to pregnancy}

EDITOR-I urge extreme caution in formulating policy on the basis of West et al's trial of the effect of low dose supplementation with vitamin $A$ or $\beta$ carotene on mortality related to pregnancy in Nepal. ${ }^{1}$ Supplements had no impact on the hypothesised outcome mortality ascribable to infection and obstetric causes but a dramatic impact on mortality due to injuries and to miscellaneous and
Supplementation was associated with 570-5. (27 February.)

uncertain causes. The authors related this discrepancy to the relative crudeness of the "verbal necropsy" technique.

Better relative risks can be determined by excluding deaths with a reliably determined cause that cannot be biologically related to supplementation-for example, injury (table). This correction alone results in statistically comparable outcomes in the placebo and vitamin A groups. Similar adjustments for chronic illness and differential loss to follow up (assuming that 10\% loss was related to mortality) strengthen the inference that vitamin A supplementation does not reduce pregnancy related mortality.

Biochemical data suggest a trend opposite to the expected dose-response relation for vitamin A. Paradoxically, the $\beta$ carotene group, with a greater reduction in mortality (relative risk 0.51), had significantly lower $(\mathrm{P}<0.002)$ serum retinol concentrations than the vitamin A group (relative risk 0.60). Furthermore, $\beta$ carotene concentrations in the placebo and vitamin A groups were identical but significantly lower than those in the $\beta$ carotene group. In the light of this biochemical heterogeneity it is inadvisable to combine two different intervention groups to compute relative risks which have spuriously narrow confidence intervals.

Vital determinants of mortality-the quality of obstetric care provided in $97 \%$ of home deliveries, comparability of severely ill referrals, and anaemia-are not quantified. Data cited elsewhere show that anaemia "was a surprising 45 percent lower in the women receiving supplements who were not infected with hookworm."' Inexplicably, the authors omitted this finding.

Other trials conducted by donors and individuals with no conflict of interest are imperative for validation, particularly in settings with at least rudimentary obstetric services. Meanwhile, it cannot be concluded from this study that vitamin A supplementation lowers pregnancy related mortality. Additional arguments against adopting a narrow approach of supplementation include logistics of weekly distribution, long term safety, cost effectiveness, and no benefits for fetal or early infant mortality. ${ }^{2}$

Finally, I question the motive and ethics of global dissemination of selective study

Recalculated impact of supplementation on mortality related to pregnancy up to 12 weeks post partum

\begin{tabular}{|c|c|c|c|}
\hline & Placebo (n=7241) & Vitamin A ( $\mathrm{n}=7747)$ & $\beta$ Carotene $(n=7201)$ \\
\hline \multicolumn{4}{|l|}{ Excluding injury } \\
\hline No of deaths & 46 & 33 & 25 \\
\hline Relative risk $(95 \% \mathrm{Cl})$ & 1.00 & $0.67(0.41$ to 1.10$)$ & $0.55(0.32$ to 0.93$)$ \\
\hline$P$ value & & 0.112 & 0.027 \\
\hline \multicolumn{4}{|c|}{ Excluding injury and chronic illness } \\
\hline No of deaths & 43 & 33 & 23 \\
\hline Relative risk $(95 \% \mathrm{Cl})$ & 1.00 & $0.72(0.44$ to 1.18$)$ & 0.54 (0.31 to 0.94$)$ \\
\hline $\mathrm{P}$ value & & 0.194 & 0.028 \\
\hline \multicolumn{4}{|c|}{ Excluding injury and chronic illness and adjusted for loss to follow up } \\
\hline No of deaths & 47 & 40 & 27 \\
\hline Relative risk $(95 \% \mathrm{Cl})$ & 1.00 & $0.80(0.51$ to 1.26$)$ & $0.58(0.35$ to 0.98$)$ \\
\hline $\mathrm{P}$ value & & 0.337 & 0.040 \\
\hline
\end{tabular}

findings one year before peer reviewed publication. ${ }^{2}$ I hope that the authorities are not mesmerised into putting into operation the magic pill approach, which will certainly compete with budgets allocated for essential obstetric care.

Division of Clinical Epidemiology, Department of Pediatrics, Maulana Azad Medical College, New Delhi 110 002, India

jiap@ren.nic.in

1 West KP Jr, Katz J, Khatry SK, LeClerq SC, Pradhan EK, Shrestha SR, et al. Double blind, cluster randomised trial of low dose supplementation with vitamin $A$ or $\beta$ carotene on mortality related to pregnancy in Nepal. BMJ 1999;318: 570-5. (27 February)

2 United Nations Children's Fund. Vitamin A supplements dren 1998. Oxford: Oxford University Press, 1998:12-3.

\section{Slight modifications in definitions could} alter interpretation of results

EDITOR-A study in Nepal with 14948 and 7241 pregnancies in vitamin $\mathrm{A}$ or $\beta$ carotene intervention and placebo arms respectively showed a $40 \%$ reduction in maternal mortality. ${ }^{1}$ Such a study should have been designed with at least 20000 and 10000 pregnancies respectively.

Because few deaths related to pregnancy occurred, slight modifications in defining maternal mortality, the length of the postpartum period, the choice of denominator, or the "verbal necropsy" algorithm could alter the significance and interpretation of results. For example, in the vitamin A group, changing the definition from pregnancy related mortality (up to 12 weeks) to the conventional maternal mortality ratio (up to 6 weeks, excluding injury) means results were no longer significant. Examination also shows that the observed effects were strongest in the $7-12$ week period $(\mathrm{P}=0.08)$ (which is outside the definition in the international classification of diseases, 10th revision) and in deaths with uncertain causes, with no information, due to chronic illness, and of indirect obstetric causes.

We question whether the effect seen is specific to maternal mortality or part of a reduction in all cause adult female mortality. The authors should have provided data on all cause female mortality to facilitate interpretation. We postulate three scenarios: $(a)$ the reduction is specific to maternal but not to other female causes, indicating a successful maternal health intervention; $(b)$ the reduction is in both maternal and other female causes, indicating a successful all cause adult female mortality intervention; or $(c)$ the reduction in maternal causes is offset by an increase in other female causes, leaving the total all cause adult female mortality the same in the two arms. It seems implausible that supplementation would decrease maternal mortality while increasing female mortality due to other causes, which suggests that the observed reduction in maternal causes results from random fluctuation, exacerbated by the small numbers and definitional issues described above, and by the differential loss to follow up. ${ }^{2}$

\section{H P S Sachdev professor} save preonant women's lives. In: The state of the world's chit 
The absence of information on female deaths and the minimal effect on direct obstetric deaths make it premature to start action programmes. Neither historical reviews in Western countries ${ }^{3}$ nor reviews of obstetric literature identify a plausible contribution of nutritional factors to the decline in maternal mortality. Even if the reduction is shown to be specific to maternal mortality, the study leaves us uncertain whether the appropriate intervention is to give vitamin $A$ or $\beta$ carotene, whether the dietary supplement should be delivered before conception or antenatally, and whether it is feasible for programmes to administer supplementation weekly.

Carine Ronsmans lecturer, Maternal and Child Epidemiology Unit

Oona Campbell senior lecturer, Maternal and Child Epidemiology Unit

Martine Collumbien research fellow, Centre for

Population Studies

London School of Hygiene and Tropical Medicine, London WC1B 3DP

1 West KP Jr, Katz J, Khatry SK, LeClerq SC, Pradhan EK, Shrestha SR, et al. Double blind, cluster randomised trial of low dose supplementation with vitamin $A$ or $\beta$ carotene on mortality related to pregnancy in Nepal. BMJ 1999;318 570-5. (27 February.)

2 Olsen SF. Effect of vitamin A and $\beta$ carotene supplementation on women's health. BMJ 1999;318:551-2. (27 February.)

3 Loudon I. Death in childbirth: an international study of maternal care and maternal mortality, 1800-1950. Oxford: Clarendon Press, 1992

\section{Authors' reply}

EDITOR-Intention to treat analysis of mortalities across randomised supplement groups based on all deaths and pregnancies during a common follow up period, adjusted for design effect, provides a valid basis for inference. This showed significant reductions of $40 \%$ and $49 \%$ in the mortality of mothers through three months post partum with vitamin $A$ and $\beta$ carotene respectively. Stratification by time related to pregnancy and apparent causes of death raised questions and reduced precision but does not invalidate intention to treat findings. Despite the inability of "verbal necropsy" to discern causes of death, reduced risk of sepsis offers one plausible hypothesis.

Concern is expressed that many of the 157 women lost to follow up about two weeks post partum may have died, distorting treatment effects. More likely, these women moved to homes outside the study area after giving birth. Sachdev's insistence on no effect, based on his assumption that $10 \%$ of these women died, furthered by his analysis of adjusted data, is simply untenable, given an expectation of 0.5 deaths in all 157 women based on observed rates among over 20000 women. In response to Ronsmans et al, pregnancy related effects are not offset by an increase in adult female mortality, although impact seems minimal beyond six months post partum (preliminary data).

We had planned to analyse the combined effects of vitamin $A$ and $\beta$ carotene from the outset. $\beta$ Carotene is the most efficiently converted provitamin A carotenoid and the main dietary source of vitamin $\mathrm{A}$ in south Asia. ${ }^{2}$ Typically, improved dietary intake involves raising both provitamin and preformed vitamin A. Both supplements improved status, although $\beta$ carotene had less impact. ${ }^{3}$ Thus overlapping nutritional roles, a priori intentions, and comparable empirical results justified reporting pooled and separate treatment effects.

Lack of a linear relation between mid-pregnancy serum retinol concentrations and risk reduction in maternal mortality should not be surprising. Once normalised, circulating retinol is homoeostatically controlled. Animal depletion studies also show a reversal in mortality with small additions of vitamin A before tissue concentrations respond. ${ }^{4}$ A larger measured effect of $\beta$ carotene on mortality, given less impact on circulating retinol and night blindness, ${ }^{3}$ could be due to chance or effects beyond its provitamin role. An antioxidant hypothesis seems plausible in malnourished women exposed to multiple factors that could increase oxidative stress-for example, infection, pregnancy, heavy work, sunlight, smoke.

We agree that it is too early to establish policy from our findings and that replication is needed. Still, improving vitamin $A$ or $\beta$ carotene intake may enhance maternal survival.

Keith P West Jr professor

kwest@jhsph.edu

Joanne Katz professor

Department of International Health,

Johns Hopkins University, Baltimore, MD 21205 ,

USA

Subarna Khatry national study director

Kathmandu, Nepal

1 Green HN, Pindar D, Davis G, Melanby E. Diet as prophylactic agent against puerperal sepsis-with special prophylactic agent against puerperal sepsis-with special
reference to vitamin $\mathrm{A}$ as an anti-infective agent. $B M$ J reference to

2 Gopalan C, Rama Sastri BV, Balasubramanian SC, Narasinga Rao BS, Deosthale YG, Pant KC. Nutritive value of inga Rao BS, Deosthale YG, Pant KC. Nutritzve value of

Indian foods. New Delhi, India: ICMR Offset Press, 1989.
Christian P, West KP Jr, Khatry SK, Katz J, LeClerq SC, 3 Christian P, West KP Jr, Khatry SK, Katz J, LeClerq SC, tion reduces but does not eliminate maternal night blindness in Nepal. J Nutr 1998;128:1458-63.

4 West KP Jr. Dietary vitamin A deficiency: effects on growth, infection, and mortality. Food Nutr Bull 1991;13:119-31.

\section{Human rights are based on consensus}

EDITOR-Doctors, among all those whose work is based on the scientific method, must guard most against taking apparently logical arguments too far. Barlow's rejection of the proposal that health care is a human right is such a case. ${ }^{1}$ He bases this rejection on three points: that health care is difficult to define; that it is not clear whose duty it is to provide health care; and that "it is difficult to find any rational or utilitarian basis" for viewing health care as a human right.

The value and justification of human rights is not that they can be derived from abstract principles but that they represent a consensus view of what all of us owe to each other. In this way human interdependence has a chance of producing positive rather than negative outcomes. The Universal Declaration of Human Rights of 1948 is the most widely accepted expression of this consensus and has been signed up to by many nations whose people would not agree on religious or social principles. ${ }^{2}$

Article 25 of the universal declaration states: "Everyone has the right to ... medical care." On the basis of this, health care is a human right. It is this that makes tackling the difficulties of deciding appropriate and affordable levels of care so urgent, not just for doctors but for politicians, economists, and the rest of us.

Diarmid J G Weir former general practitioner 8 Alnwickhill Gardens, Edinburgh EH16 6NF djgw@febl.abel.co.uk

1 Barlow P. Health care is not a human right. BMJ 1999;319:321. (31 July.)

2 Universal Declaration of Human Rights, English version. www.un.org/Overview/rights.html.

\section{When I use a word. .}

\section{"Liar" can indeed be found in dictionary}

EDITOR-Armed with information provided in the hallowed pages of the $B M J,{ }^{1} \mathrm{I}$ bet my son that he could not find the word "liar" in our copy of the 1972 edition of Chambers Twentieth Century Dictionary. He found liar to be present at the foot of page 757, cross referenced to "lie" on page 759. Aronson should check his sources.

Judith C Simpson senior clinical medical officer 88 Stewarton Drive, Cambuslang, Glasgow G72 8DJ

judithsimpson@lineone.net

Competing interests: I lost 50 pence. (Perhaps that serves me right for insider dealing.)

1 Aronson J. When I use a word ... BMJ 1999;319:494. (21 August.)

\section{Communication is the key}

EDITOR-I was a young general practitioner in my first year of private practice and did not realise that a 4 year old does not understand that breathing is an unconscious normal physiological process. I asked a little boy to sit up for auscultation of his chest and said, "Breathe." The child got into a panic and turned to his mother, saying: "Mommy, I can't breathe."'

It takes time to become a good general practitioner and to learn how to communicate with all age groups.

L Reinecke radiation oncologist

Rand Clinic, Johannesburg, South Africa leopoldr@netactive.co.za

1 Aronson J. When I use a word ... BMJ 1999;319:494. (21 August.)

Rapid responses
Correspondence submitted electronically
is available on our website www.bmj.com

